\title{
Independent Component Analysis in development of Chinese Agriculture insurance
}

\author{
Chen Xiaoxia \\ School of Economy and Law, University of Science and Technology of Liaoning \\ Anshan, China \\ e-mail: itteam@126.com
}

\begin{abstract}
Independent Component Analysis is a useful method to find some internal keyelement which play an important role in the development. This paper uses ICA to analyze agriculture insurance to try to find the major factorwhich has great impact. We take FastICA as analysis tool and designed parameters. According to the experiment results and prior knowledge, some key elements are picked up from the independent components. Then, further discussionis made to quest how the elements work. Finally, this paper gives some recommendations for benign development of agriculture insurance.
\end{abstract}

Keywords:Independent Component Analysis, Agriculture Insurance, FastICA

\section{INTRODUCTION}

Agriculture is important for every country, especially in China, considering the huge population, whichis the core of the economic development. Also, we can say that it's an uncertain business, partly due to its high dependence on the weather.Agriculture is disaster-prone. Disasters happen frequently in China, when the rural people live tough life. Then Agriculture insurance may be a more attractive channel for government support to rural livelihoods and risk mitigation than ex-post disaster transfers, which offer no ex-ante guarantee to farmers and may therefore have limited impact on ex-ante decisions, or loan waiver or input subsidy programs, which may adversely distort behavior.

However, making the provision of agriculture insurance is a challenge task and how to popularize the appropriateprovision is also a problem, especially in China the developing country with the frail agriculture infrastructure.In recent decades, the Chinese government increasescapital investment on the insurance for agriculture. It also wants to form a comprehensive planned mechanism to mitigate the risks of natural perils on farm production.

Agriculture insurance has greater effect on motivating the output offarm production even than agriculture loan ${ }^{[1]}$. According to the data published by the CIRC (China Insurance Regulatory Commission), from 2012 to 2014, agriculture insurance income grows rapidly:

In 2011,total amount of insurance income is 13.568 billion Yuan with an increase of 189 million Yuan comparing to 2010, and there costs 10.069 billion on premiums. In 2012, the total amount of income is 17.38 billion Yuan with the $28.1 \%$ year-on-year growth, providingmore than 652.3 billion Yuan premiums, more than 16 million people benefit from it. In 2013, the overall income is 24.06 billion Yuan with the $38.3 \%$ year-on-year growth, providing more than 900 billion Yuan premiums, more than 28.2 million people benefit from it.Particularly in the July 21rainstorm disaster and Bolaven Typhoon.

However, Chinese agriculture insurance market is still in infancy.Though, November 2012, Agricultural insurance regulations was promulgated by China's State Council, whichformalizes specification for support measures, implying the government wants to regulate the agriculture insurance market. The narrow insurance coverage and insurance diversity shortage are prominent problems in popularizing agriculturalinsurance. How to stimulate the development of agriculture insurance effectively is another important issue. Researchers around the global focus on finding the inner factors which impact the insurance growth.

The literature[2]conclude that the main factors impact on the demand for crop insurance is the expected income of farmers, income variety and the risk aversion rate. And thenthe literature[3]tells us that, instead of risk aversion rate, what predominantly affect the purchasing enthusiasm for insurance is the fiscal subsidy ${ }^{[4]}$. To draw the conclusion there are some inverse relationships between disaster assistance andinsurance purchases. Their analysis also suggests that farmers which buy insurance and whichreceive disaster payments tend to have higher returns to farming. The literature [5] take India as an example, it shows that viable premium rate need to cover pure risk, administrative cost and reasonable returns, which means some policy-oriented insurance should be adopted.

We can find that there exist many factors that have complex influence on the insurance purchasingbehavior. This paper intends to find some components thatare independent with others. Then we can take a deep analysis into them. Without uncertain interference, this paper draws some interesting results and organizes as follows. Section 2 summarizes the ICA (Independent Component Analysis) used in the paper to analyzedata. Section 3 presents our procession and the result of analysis with ICA. Then, section 4 discusses the result obtained from the experiment. The finalconclusion is given in section 5 .

\section{INDEPENDENT COMPONENT ANALYSIS}

Independent component analysis (ICA) isoriginal form the cocktail party problem, which define a situation that in a cocktail party where many people are speaking simultaneously, so we have some microphones, which located in different locations to record the signals which are weighted sum of speech signals emitted by these speakers.

ICA is a method in which the goal is to find a linear representation of non-Gaussian data so that the components are statistically independent, or as 
independent as possible to settle the cocktail party problem. The ICA model can be described in Figure. 1 as

follows $^{[6]}$.

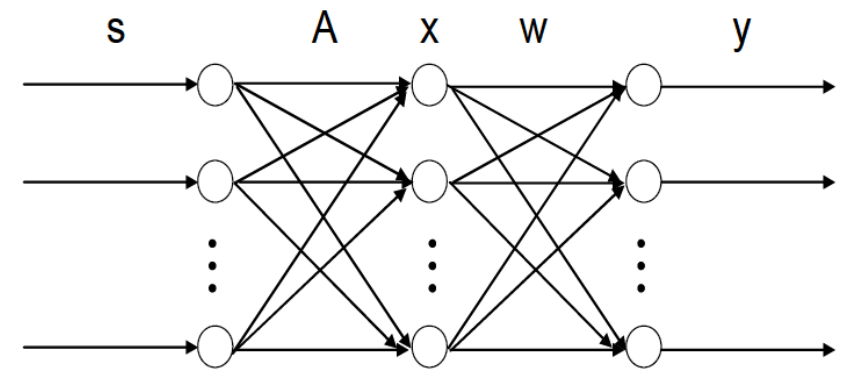

Figure.1 ICA model

Where S represents speakers, which is an n-dimensional random vector that assumedmutually independent, $\mathrm{x}$ is an observed $\mathrm{m}$-dimensionalvector. Let us denote $S$ and X respectively: $S=\left[s_{1}(t), s_{2}(t) \cdots, s_{N}(t)\right]^{T}$, $X=\left[x_{1}(t), x_{2}(t) \cdots, x_{N}(t)\right]^{T}$

The matrix $X$ are generated asa linear mixture of n-dimensional independent componentss $(\mathrm{t})$ denoted by $X=A \quad S$ A is a hybrid matrix. Both the matrix $\mathrm{A}$ and the $\mathrm{s}(\mathrm{t})$ areunaware, when we can only observe $\mathrm{x}(\mathrm{t})$. In the real case, thereis more common to see noisy ICA model. The noisy ICAmodel can be expressed as: $X=A \quad S+n$. Though estimating the matrix $A$, we can compute its inverse, say $W$, and obtain the independent component simply by: $S=W \quad X$

ICA is very closely related to the method called BSS (blind source separation) or blind signal separation. A source means here an original signal, i.e. independent component, like the speaker in a cocktail party problem. Blind means that we know very little, if anything, on the mixing matrix, and make little assumptions on the source signals. ICA is one method, perhaps the most widely used, during various areas such as feature extraction, blind signal separation, financial data analysis, vision procession, and so on.

In the financial sector, ICA can reveal the driving mechanism hiding behind the enormous data. Recent years, researcher find ICA is complementary of PCA (principle Component Analysis), which can expose the basic structure of data, to determine the elements push situation forward. The literature[7] shows the elements influence the stock market and the returns. ICA also can be a guidefor policy maker to regulate the finical market. The literature[8] uses ICA to construct spot portfolio which has better linkage with stock index futures, whose result indicate that this method can achieve desired effect.

This paper inspired by the researchers above,we also try to use ICA to find the factors with essential function for the development of agriculture insurance.

\section{DATA ANALYSIS}

Domestic researchers focus on the factorthat can give a positive impact on the growth of agriculture insurance. The literature [9] points out that the most essential factor impact the development of agriculture insurance is the fiscal subsidy. The literature [10] shows that during the fiscal subsidy high correlation shows up between insurance demand and farmers' income. The paper also mentions that the awareness of farmers is important either. The literature[11] via empirical analysis shows that the growth of agricultural production, farmers'income, disaster rate and governmental fiscal subsidy policy are the most vital factors to affect the development of China's agricultural insurance. Through the comparison between other countries ${ }^{[12]}$,it finds the fact that Fiscal subsidy plays an important role in agriculture insurance, which displays a positive amplification effect on fiscal input. Take policy agriculture insurance ${ }^{[13]}$ of Anshan city for example, it shows that combine the government, social power can implement the policy agriculture insurance quite well. It analyzes the plight of implement agriculture insurance ${ }^{[14]}$ in Hebei prov., it finds that weak awareness of farmers on purchase insurance, low enthusiasm of insurance company, poor support by government and so on. Through constructing demand model ${ }^{[15]}$ which parameterize some demand conditional ingredients showing that policy-orientedmeasures should be adopted. It points out that the contradiction between the farmers' objective needs for agricultural insurance ${ }^{[16]}$ and the insufficient agricultural insurance products is widespread. The low quality of agricultural insurance products, the immaturity of catastrophe risk disperse system and the deficiency of transforming agricultural insurance research achievements into reality are handicap the evolution of agricultural insurance. It points thatfactors such asaccess ${ }^{[17]}$ to credit, education, off-farm income, etc. have significantly influenced the adoption of insurance.

In this section we will analyze data obtained from Year book of China's statistics, Year book of China's agriculture, Year book of China's fiancé, Year book of China's insurance and other references. This paper excludes the data of some provinces where agriculture insurance is closed down during a period, and hasn't launched the rural compensation of agriculture insurance. We use the tool of FastICA to help analyzing data try to find the driving elements lay behind the enormous data.

\section{A. FastICA}

FastICA isan efficient and popular algorithm for independent component analysis invented by AapoHyvärinen at Helsinki University of Technology. The following Figure 2 is the interface. 


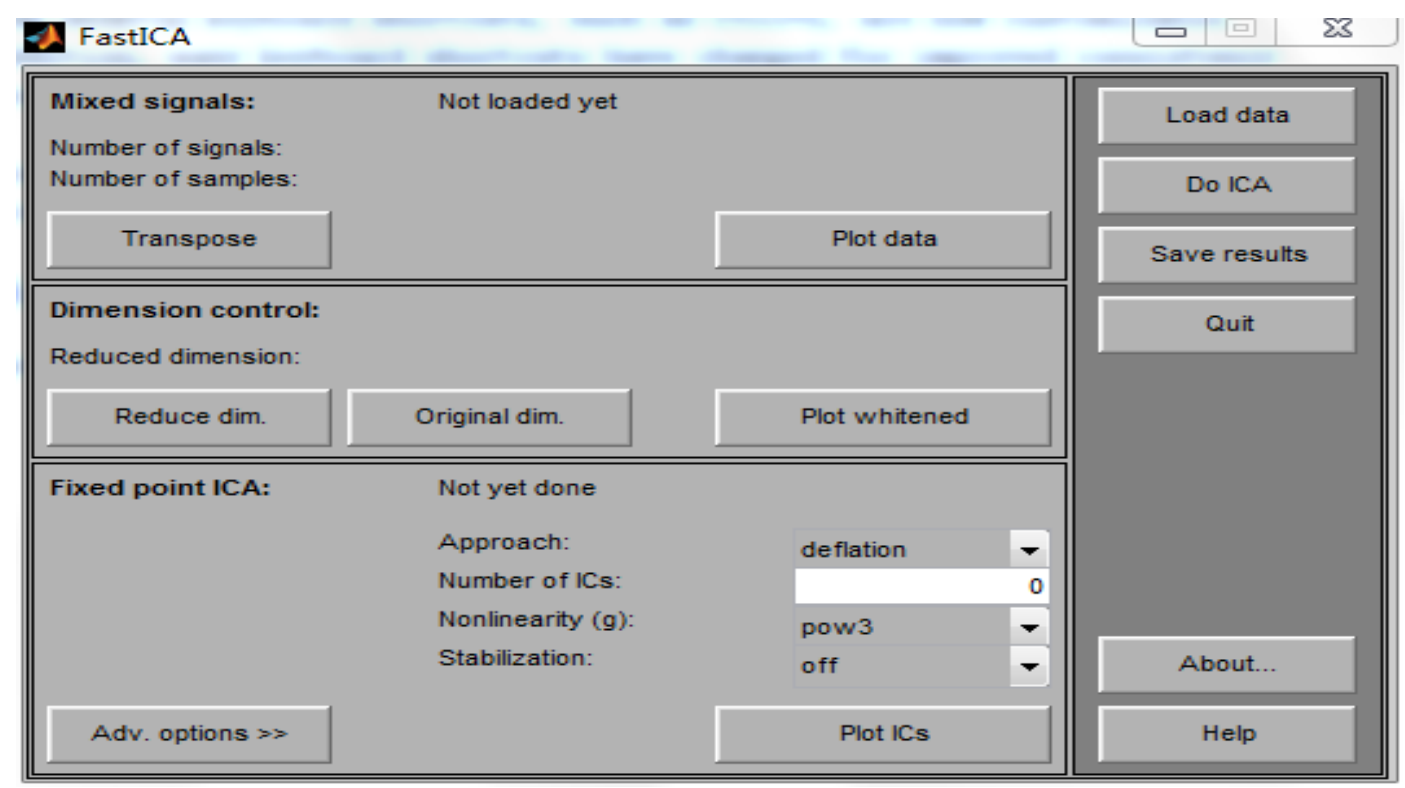

Figure 2 FastICA operator interface

\section{B. Data Procession}

Considering the factors impact on the development of agriculture insurance, this paper extract the following targets as the prior knowledge, they are:

a) Gross Agricultural production, is the price of total agricultural production from all the areas of China. It reflects the development of the rural economy.

b) Annual per capita income of rural householdsis the disposable income of rural residents which reflects the income of the rural residents.

c) Agricultural disaster areas are the total areas affected by two main calamity, inundation and drought, which reflects the losses of the agriculture.

d) Agriculture insurance's proportion is the outcome of the division between agriculture insurance total income and property insurance total income.

e) Agricultural disaster reliefis the financial subsidy for the disaster area to relieve rural resident who suffer from disaster at some extent.

f) Premium subsidy is the compensation from state finance to compensate rural people who purchase the agriculture insurances.

g) Culture factor in rural area is considered in this paper which can affect rural people for understanding the function of insurance to avoid risk.

As the input to the FastICA, we chose ten years' (2002-2011) agriculture insurance statistical data in months. Then we get a 1210 Matrix, the following Figure 3 shows the details about the Matrix. 


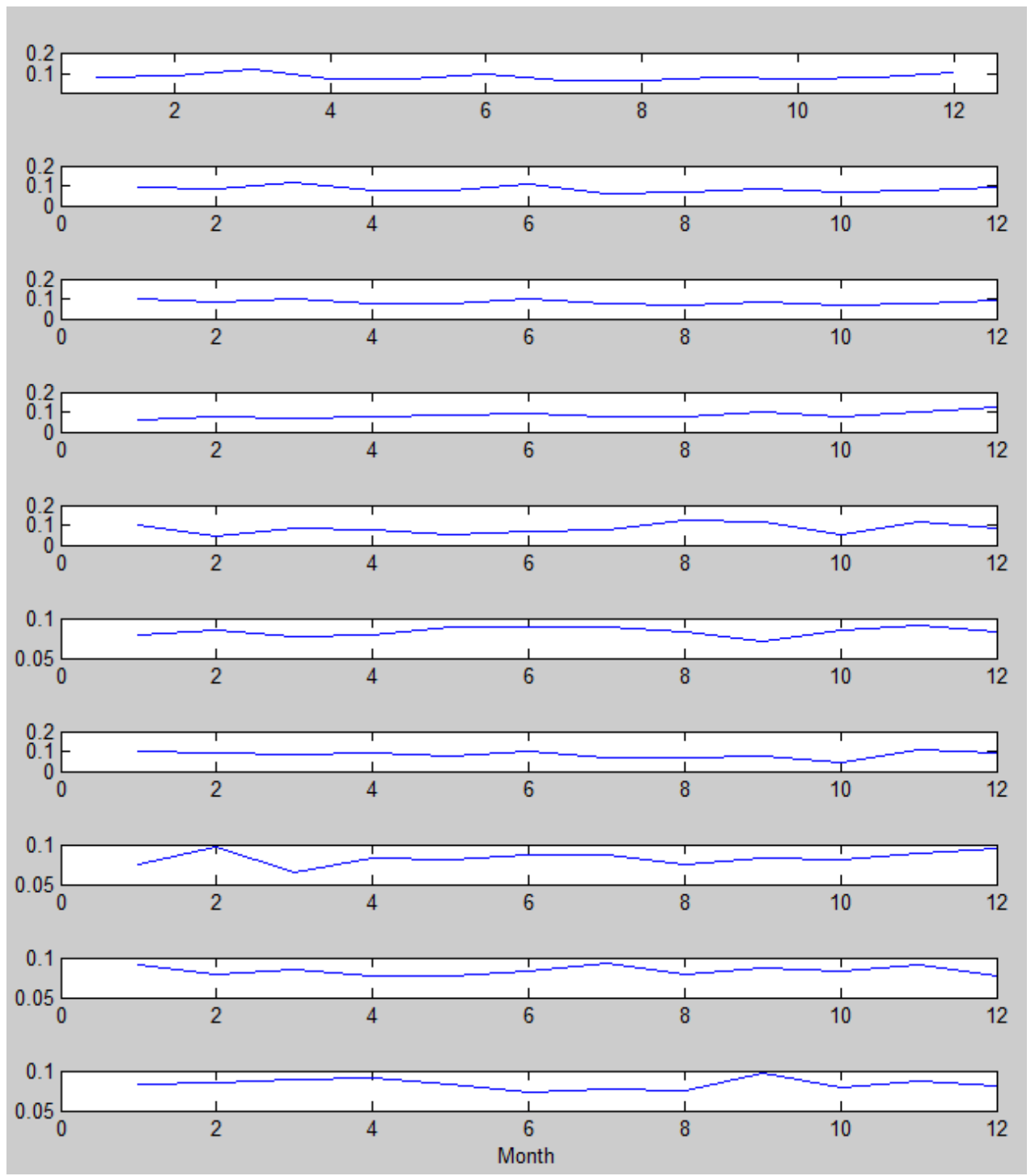

Figure 3 statistical data of insurance income

After setting some parameters, Figure 4 shows the independent components as follows:

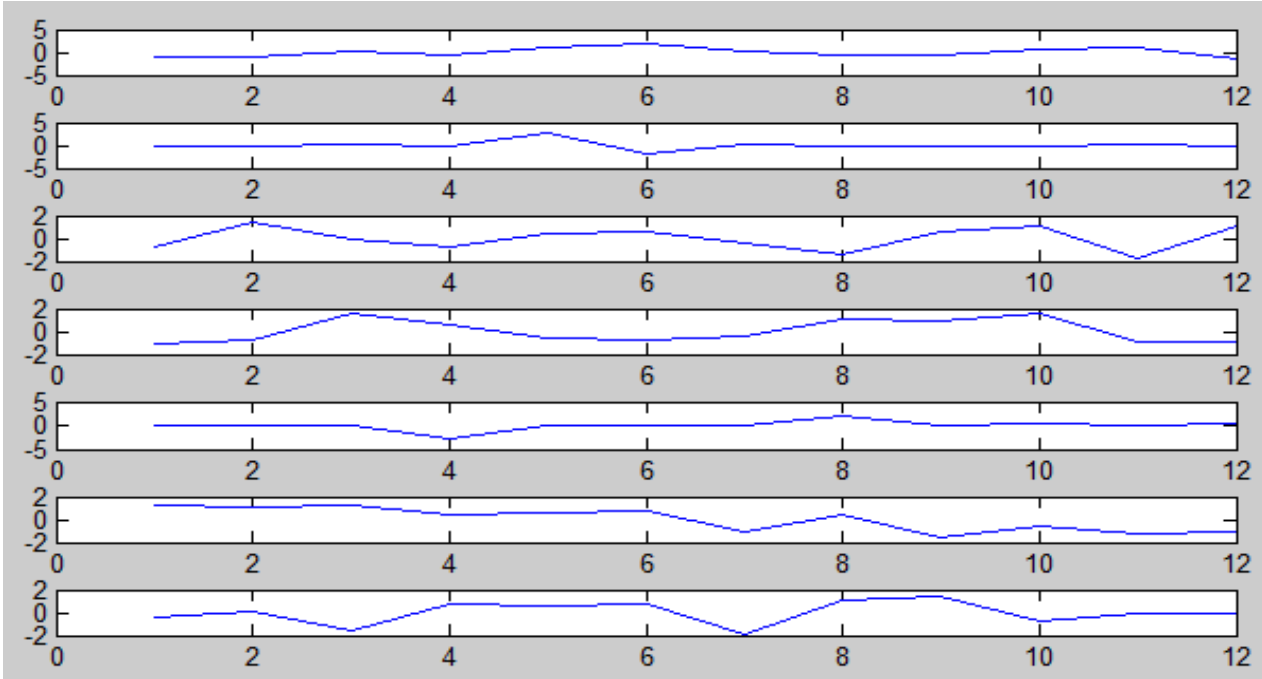

Figure 4 independent components

Figure 4 gives five independent components. Because of the prior knowledge, we can find that the independent component which greater effectnamed the premium subsidy. Then,bothannual per capita income of rural householdsand gross Agricultural production have notable impact. We can't find the culture fact works 
effectively. Finally, both disaster areas and the rural compensationhave the least effect. In the next session we will get further discussion.

\section{DISCUSSION}

Based on the result of FastICA, we can get the following results:

a) Premium subsidy plays a pivotal role whichcan significantly stimulate the enthusiasm of rural residents about the agriculture insurance which is the characteristic of China in the development of agriculture insurance. Therefore, to construct a government-finance-supported system is the premise that can guarantee agriculture insurance sustainable expansion.

b) Gross Agricultural production andannual per capita income of rural households arekey elements for the scale of agriculture insurancethat are indexes of agriculture economic environment. Under the favorable economic environment, the disposable income can grow which means rural residents get enough capital to buy insurance.

c) Disasters can't significantly stimulate rural residents'purchasingbehaviorthat has various reasons. The main point is that the weak consciousness for avoiding risk which has little relation with the culture factor showing a fact that many rural residents have no knowledge about the insurance including what insurance

\section{REFERENCES}

X. N. Wang, Agricultural loans,Effect of agricultural insurance on agricultural output-The evidenceofChineselevel units from.2004-2009, Chinese rural economy, 2012(10): p. 44-51.(In chinese)

P.B..Hazell, C. Pomareda, and A. Valdés, Crop insurance for agricultural development: Issues and experience. 1985: International Food Policy Research Institute.

R.E.Just, L. Calvin, and J. Quiggin, Adverse selection in crop insurance: Actuarial and asymmetric information incentives. American Journal of Agricultural Economics, 1999. 81(4): p. 834-849.

B.K Goodwin and R.M. Rejesus, Safety Nets or Trampolines? Federal Crop Insurance, Disaster Assistance, and the Farm Bill. Journal of Agricultural and Applied Economics, 2008. 40(2): p. $415-429$

[5] A.H. Bobade and S.S. Mahajan, Is the Crop Insurance a Remedy on Risk Management in Agriculture especially in Drought Prone Area?: It's Performance in Khatav Taluka of Satara District. Review of Research, 2012. 1(5).

[6] X.Yu, C. Lu, and J. Shen. Denoising of tube-type bottle image based on independent component analysis and nonsubsampled contourlet transform. in Signal Processing Systems (ICSPS), 2010 2nd International Conference on. 2010. IEEE.

[7] Y. S. Chen, and B. Xi, Application of independent component analysis in stock analysis. 2007.(In chinese)

[8] S. L. Cai,, C. H. Guo, and X. Xu, The research on the optimal spot goods conbined strategy construction in the stock index and futures interest arbitrage. planning and management, 2012. 21(2): p. 154-161.(In chinese)

[9] K. Wang and S. Duan, The empirical analysis of many factors affect on the development of agricultured insurance in China.Insurance research, 2009(4): p. 101-105. (In chinese) for, what insurance can do and what rural residents need do. Therefore,

d) Agricultural disaster relief is the most convenient way to get subsidy during disaster that has the least relation with the growth of agriculture insurance because of the Inertia of cogitationwaiting for relief.

Therefore, we have some suggestion about our agriculture insurance:

a) Ensure the growth of agriculturaleconomics that can provide a favorable economic environment.

b) Ensure the continued income growth and the disposable incomeof the rural residents.

c) Increase state financial subsidiesthat can be treated according to different situation.

d) Intensify propaganda of agriculture insurance to strengthen insurance awareness.

e) Adjust the agricultural disaster relief appropriatelyin order to strengthening rural residents' insurance awareness.

\section{CONCLUSION}

This paper though independent component analysis to exploresome key elements which affect growth of agriculture insurance. It is convincing that ICA is a useful way to probe the internal factors hiding behind the enormous data. According to the results, we could find some really interesting information about the insurance. Finally, we give some suggestion for agriculture insurance policy construction.

[10] D. J. Liu and X. S. Zhang, The analysis of related factors of China's agricultural insurance demand. Journal of Jiangxi University of Finance and Economics, 2011. 5: p. 009.(In chinese)

[11] R. Wang, The empirical analysis of factors affecting the development of agricultural insurance in China. Journal of Beijing Technology and Business University (Social Science Edition, 2012. 27(6).(In chinese)

[12] Fei, Z., Investigation on the Amplification Effect of Agricultural Insurance on Fiscal Input. Insurance Studies, 2011. 9: p. 002.

[13] Chen, L. Discussion of the policy agricultural insurance development-Analysis based on the operation of the policy agricultural insurance in AnShan of liaoning province. in E-Business and E-Government (ICEE), 2011 International Conference on. 2011. IEEE.

[14] Ling, M., W.-g. Wang, and X.-y. Wang, The Plights and Countermeasures in the Implementation of Distinctive Agriculture Insurance of Hebei Province. Asian Agricultural Research, 2011. 3(03).

[15] HUANG, Y.-j., J.-w. LIN, and S.-y. ZOU, Model Construction and Theory Reconsideration on Demand for Agriculture Insurance in China. East China Economic Management, 2010. 6: p. 013.

[16] XiaoJuan, Y., L. BuChun, and L. Yuan, Practice and research progress on agriculture insurance in China during the past ten years. Journal of Agricultural Science and Technology (Beijing), 2012. 14(2): p. 22-30.

[17] Bodiul, A., Efficiency of insurance in agriculture of Republic Moldova in the market economy conditions. Development, 2012. 